\author{
Mary Ann Lielest, Inc. Fo puldishers
}

\title{
Secreted Endothelial Cell Factors Immobilized on Collagen Scaffolds Enhance the Recipient Endothelial Cell Environment
}

\author{
Charlotte Hamilton and Anthony Callanan*
}

\begin{abstract}
Strategies to design novel vascular scaffolds are a continuing aim in tissue engineering and often such designs encompass the use of recombinant factors to enhance the performance of the scaffold. The established use of cell secretion utilized in feeder systems and conditioned media offer a source of paracrine factors, which has potential to be used in tissue-engineered (TE) scaffolds. Here we utilize this principle from endothelial cells (ECs), to create a novel TE scaffold by harnessing secreted factors and immobilizing these to collagen scaffolds. This research revealed increased cellular attachment and positive angiogenic gene upregulation responses in recipient ECs grown on these conditioned scaffolds. Also, the conditioning method did not affect the mechanical structural integrity of the scaffolds. These results may advocate the potential use of this system to improve vascular scaffolds' in vivo performance. In addition, this process may be a future method utilized to improve other tissue engineering scaffold therapies.
\end{abstract}

Key words: angiogenesis; biomaterials; gene expression; growth factor; tissue engineering

\section{Introduction}

A continuing challenge faced in vascular tissue engineering is how to improve treatments for cardiovascular disease and other such arterial conditions. Current strategies include a number of scaffold materials and/or therapies that mimic the native vessel wall, restore in situ endothelialization, promote extracellular matrix (ECM) production, inhibit thrombogenicity, reduce inflammation, and help stimulate neovascularization and angiogenesis. ${ }^{1,2}$ Tissue engineering has utilized a range of biomaterials, including decellularized $\mathrm{ECM}^{3,4}$ synthetic biopolymers, ${ }^{5}$ and biodegradable polymers to create tissue-engineered (TE) vascular grafts. ${ }^{6-10}$

Some of the most common types of scaffold are collagen based ${ }^{11-13}$ and have been shown to promote cell attachment, migration, proliferation, differentiation, and ECM production during remodeling and regeneration. ${ }^{14}$ More recently, they have incorporated growth factors and proteins such as vascular endothelial growth factor (VEGF) $)^{15,16}$ and angiopoietin-1 (Ang1). ${ }^{17,18}$ The use of growth factors and proteins has predominately focused on the concentration and release kinetics of these factors, whether they are designed to be retained within the scaffold ${ }^{19,20}$ or released. ${ }^{21-23}$ Mainly, the purpose is to enhance the cell functionality, and contact and interact with the in vivo tissue. ${ }^{24}$

In addition, cell secretion can also be a direct or indirect source of paracrine growth factors and proteins. Consequently, this may be one way to partially recapitulate the intrinsic cell environment by using the cell secretion. The principle offered from cell secretion has been utilized directly in the cell culture as cell feeder layer systems to provide paracrine factors to recipient cells. ${ }^{25}$ Cell feeder layers have been widely used to maintain pluripotency of human-induced pluripotent stem cells ${ }^{26,27}$ and human embryonic stem cells. ${ }^{28,29}$ 
They have also shown promise in tissue regeneration, ${ }^{30,31}$ including secretion from mesenchymal stem

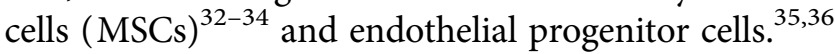

In this in vitro study, we use these principles of the feeder layer cell secretion technique to generate cell conditioned media and incorporate this into a novel TE scaffold. We achieve this by utilizing endothelial cell-secreted factors (ECSFs) and immobilize these to collagen scaffolds and test for improved functionality by the attachment of recipient endothelial cells (ECs).

\section{Materials and Methods}

Preparation and experimental setup

Cell culture. Human umbilical vein endothelial cells (HUVECs) from an infant male Caucasian donor were obtained cryopreserved (500,000 cells) at passage 1 (Pro$\mathrm{moCell} \mathrm{GmbH}$ ) and cultured and expanded to passage 5 (P5) in a humidified atmosphere of $5 \% \mathrm{CO}_{2} / 37^{\circ} \mathrm{C}$ in $\mathrm{T}$ 75 vented flasks (Corning ${ }^{\circledR}$ ) and grown to $80 \%$ confluency. HUVECs were cultured according to a previously used endothelial cell culture protocol, ${ }^{37-39}$ and in brief, MCDB 131 medium (Life Technologies ${ }^{\mathrm{TM}}$ ) was supplemented with $2 \%$ fetal bovine serum (FBS; ThermoFisher Scientific); $1 \%$ L-glutamine; $1 \%$ penicillin/streptomycin (Life Technologies); $1 \mathrm{mg} / \mathrm{L}$ hydrocortisone; $50 \mathrm{mg} / \mathrm{L}$ of ascorbic acid (Sigma); $2 \mathrm{mg} / \mathrm{L}$ fibroblast growth factor; $10 \mathrm{mg} / \mathrm{L}$ epidermal growth factor; $2 \mathrm{mg} / \mathrm{L}$ insulin-like growth factor; and $1 \mathrm{mg} / \mathrm{L}$ VEGF (PeproTech).

Basal media. Basal media (BM) consisted of MCDB 131 medium with $2 \%$ FBS omitted and all supplements (listed above) added for serum-free cell culture conditions. For experimental conditions, $5 \mathrm{~mL}$ of the BM was incubated in a humidified atmosphere of $5 \%$ $\mathrm{CO}_{2} / 37^{\circ} \mathrm{C}$ in $\mathrm{T}-75$ vented flasks.

Cell conditioned BM. HUVECs at P5 were washed thrice using D-phosphate-buffered saline (PBS)/CaCl and $\mathrm{MgCl}_{2}$ free (Sigma). HUVECs were then cultured in $5 \mathrm{~mL}$ of BM for $48 \mathrm{~h}$, incubated in a humidified atmosphere of $5 \% \mathrm{CO}_{2} / 37^{\circ} \mathrm{C}$ in $\mathrm{T}-75$ vented flasks, and grown to no more than $70-75 \%$ confluency to obtain cell conditioned BM. These media are generally known as cell conditioned media, and for simplicity, further referred to as adjusted $\mathrm{BM}(\mathrm{ABM})$. The $\mathrm{ABM}$ were filter sterilized using a $0.22-\mu \mathrm{M}$ filter (Millex ${ }^{\circledR}$ GS Millipore) before use.

Collagen scaffolds. Scaffolds discs $(10 \mathrm{~mm}$ diameter $\times 2 \mathrm{~mm}$ thick) were punched from sheets of commer- cially available Ultrafoam ${ }^{\mathrm{TM}}$ collagen (Davol, Inc.) using a $10 \mathrm{~mm}$ disposable biopsy punch (Acuderm, Inc.) on to the surface of a sterile 1.2-mm-thick glass slide (ThermoFisher Scientific). According to the manufacturer's specifications, Ultrafoam is a waterinsoluble, partial $\mathrm{HCl}$ salt of purified bovine dermal (corium) collagen formed as a sponge with interconnected pores. Collagen scaffolds soaked in D-PBS/ $\mathrm{CaCl}_{2}$ and $\mathrm{MgCl}_{2}$ free (Sigma) served as the control groups for all experiments.

Conditioned collagen scaffolds through absorption. Scaffolds were soaked in PBS, BM, or ABM and incubated $24 \mathrm{~h}$ at $37^{\circ} \mathrm{C}$ and mildly shaken in an orbital shaker (IKA KS 400 i) at $100 \mathrm{rpm}$ in $100-\mathrm{mL}$ Duran flasks during the conditioning process. Refer to Figure 1 for schematic overview of scaffold preparation.

Conditioned collagen scaffolds via immobilization. Scaffolds were soaked for $40 \mathrm{~min}$ at room temperature with mild agitation in a $\mathrm{D}-\mathrm{PBS} / \mathrm{CaCl}_{2}$ and $\mathrm{MgCl}_{2}$ free (Sigma) solution of 1-(3-Dimethylaminopropyl)-3-ethylcarbodiimideEDC (Sigma) and $N$-hydroxysulfosuccinimide-sulfoNHS (Sigma; E/N [(1-(3-Dimethylaminopropyl)-3ethylcarbodiimide and NHS-hydroxysulfosuccinimide)]) at a concentration ratio of $16 \mathrm{mg} / 24 \mathrm{mg} \mathrm{mL}^{-1}$, respectively, and filter sterilized using a $0.22-\mu \mathrm{M}$ filter. The concentrations used were previously used concentrations for scaffolds. ${ }^{40}$ The scaffolds were then subjected to three successive soaks in fresh D-PBS/ $\mathrm{CaCl}_{2}$ and $\mathrm{MgCl}_{2}$ free (Sigma) for $10 \mathrm{~min}$, each at room temperature with mild agitation to remove any excess E/N. Scaffolds were soaked in PBS, BM, or $\mathrm{ABM}$, incubated for $24 \mathrm{~h}$ at $37^{\circ} \mathrm{C}$, and mildly shaken at $100 \mathrm{rpm}$ in $100-\mathrm{mL}$ Duran flasks during the conditioning process.

Cell seeding. P5 cells were used throughout this study at a seeding density of $5 \times 10^{5}$ cells per scaffold in $100 \mu \mathrm{L}$ media with $n=4$ for each condition. For cell seeding, cells were washed thrice using $\mathrm{D}-\mathrm{PBS} / \mathrm{CaCl}_{2}$ and $\mathrm{MgCl}_{2}$ free (Sigma) and media changed into $\mathrm{BM}$ for $24 \mathrm{~h}$ and incubated in a humidified atmosphere of $5 \% \mathrm{CO}_{2} / 37^{\circ} \mathrm{C}$ in $\mathrm{T}-75$ vented flasks. Cells were seeded on to the collagen scaffolds in serum-free BM within 12-well nonadherent culture plates (Greiner ${ }^{\circledR}$ ) and incubated for $1 \mathrm{~h}$ at $5 \% \mathrm{CO}_{2} / 37^{\circ} \mathrm{C}$. Unseeded scaffolds in each respective group served as the control. Serumfree $\mathrm{BM}(1 \mathrm{~mL})$ were then added to cover scaffolds and incubated 24 and $48 \mathrm{~h}$ at $5 \% \mathrm{CO}_{2} / 37^{\circ} \mathrm{C}$. 


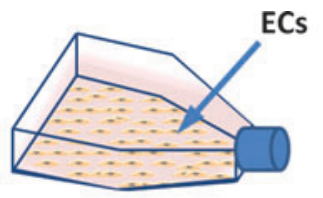

Standard EC media is changed to BM

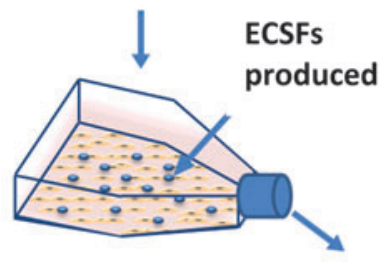

ABM extracted and incubated with scaffolds

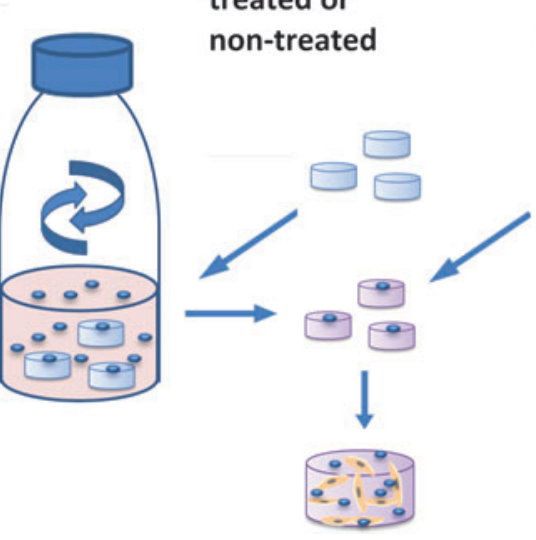

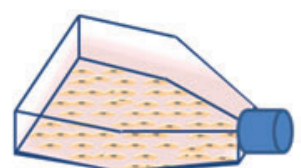

Standard EC media is changed to $\mathrm{BM}$

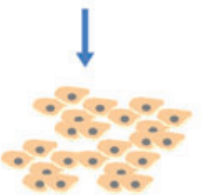

Serum-free ECs extracted and seeded on to scaffolds

FIG. 1. Schematic overview of an example of scaffold preparation using $A B M$ and the generation of autologous ECs to seed on to scaffolds. ECs cultured in standard EC media are switched to BM, this is to generate the ABM from one flask and also to generate autologous serum-free ECs for seeding on to the scaffolds from another flask. The ABM is then incubated with the scaffolds and the autologous ECs are seeded on to the ABM scaffolds. ABM, adjusted basal media; BM, basal media; EC, endothelial cell.

\section{Experimental quantification}

Protein quantitation. Media samples were then taken from the six condition groups after $24 \mathrm{~h}$ of incubation with scaffolds and before cell seeding. Samples $(n=4$ scaffolds) were analyzed in quadruplicate using a Protein Quantitation Kit (BioVision ${ }^{\circledR}$ ) according to the manufacturer's protocol, and the absorbance was measured in clear assay microplates (Greiner) using a 595-nm filter in a Modulus ${ }^{\mathrm{TM}}$ II microplate multimode reader.

Mechanical testing of collagen scaffolds. Compressional mechanics of collagen scaffolds were accessed to determine the mechanical integrity postmodification due to crosslinking, soaking, and shaking conditions. The compression testing and data interpolation are based on previously used methods for tissue-engineered scaffolds. ${ }^{41,42}$ Scaffolds $n=3$ were measured in unconfined uniaxial compression testing using an Instron Model 5540 testing machine equipped with a $50-\mathrm{N}$ load cell. The collagen scaffolds were compressed to $60 \%$ strain at a strain rate of $0.06 \mathrm{~mm} / \mathrm{sec}$. Incremental Young's modulus (i.e., the ratio of stress to strain) was calculated by measuring the slope of the stress-strain plot at incremental strain increases $(0-10 \%, 10-20 \%, 20-30 \%, 30-40 \%, 40-50 \%$, and $50-60 \%)$ as previously described. ${ }^{43}$

Scanning electron microscopy of collagen scaffolds. Scanning electron microscopy (SEM) characterized the porous architecture of the collagen scaffolds postmodification due to crosslinking and/or soaking, and then shaking conditions. The scaffolds tested, PBS unshaken, PBS shaken, PBE E/N unshaken, and PBS E/N shaken. Scaffolds were snap-frozen and then freeze dried using a FreeZone ${ }^{\circledR} 4.5$ freeze-drier (Labconco ${ }^{\circledR}$ ). The samples were then mounted on to metal stubs with doublesided carbon tape. Thin layers of a gold and palladium alloy were applied to each sample with an automated sputter coater (Polaron SputterCoater). The samples were then examined at $\times 60$ low magnification at $5 \mathrm{kV}$ (Hitach S-4700 SEM) as previously shown. ${ }^{15}$ 
CellTiter-blue ${ }^{\circledR}$ cell viability assay. The assay was performed according to the manufacturer's instructions (Promega). For the six condition groups, $n=4$ scaffolds in duplicate readings to give standard deviation of each group. A range of cell densities were also plated $\left(5 \times 10^{4}\right.$; $10 \times 10^{4} ; 25 \times 10^{4} ; 5 \times 10^{5} ; 7.5 \times 10^{5}$; and $1 \times 10^{6}$ cells/ $\mathrm{mL}^{-1}$ ) and counted to give a proportional ratio of cell number: fluorescence emitted within this standard curve. Samples were analyzed in a Modulus II microplate multimode reader using a filter of $525 \mathrm{~nm} \mathrm{Ex/}$ 580-640 nm Em.

Live/dead ${ }^{\circledR}$ viability/cytotoxicity assay. This assay was performed according to the manufacturer's protocol (Molecular Probes ${ }^{\mathrm{TM}}$ Life Technologies) for fluorescence microscopy on the seeded scaffolds. The working concentration of the calcein $\mathrm{AM}$ and $\mathrm{EthD}-1$ dyes was diluted to 0.2 and $0.4 \mu \mathrm{M}$, respectively, from the suggested working concentrations of 2 and $4 \mu \mathrm{M}$, respectively. Scaffolds were washed thrice to remove excess dye in D-PBS/ $\mathrm{CaCl}_{2}$ and $\mathrm{MgCl}_{2}$ free (Sigma) and placed on a well slide with $25 \mathrm{~mm}$ cover-slip (Scientific Laboratory Solutions). Microscopy was performed using a Zeiss Axio Imager fluorescent microscope using a $40 \times$ objective.

DNA quantitation. Cell-seeded scaffolds after the 24and 48-h growth periods were snap-frozen and stored at $-20^{\circ} \mathrm{C}$. Scaffolds were then freeze-dried overnight using a FreeZone 4.5 freeze-drier (Labconco) to remove any residual water content before DNA extraction. The scaffolds were then digested in a solution of D-PBS/ $\mathrm{CaCl}_{2}$ and $\mathrm{MgCl}_{2}$ free (Sigma), containing $2.5 \mathrm{U} / \mathrm{mL}$ papain extract (Sigma), $5 \mathrm{mM}$ cysteine-HCl (Sigma), and $5 \mathrm{mM}$ EDTA (Sigma), and samples were incubated overnight at $60^{\circ} \mathrm{C}$. Cell extracts $(n=4)$ of $5 \times 10^{5}$ cells frozen at $-20^{\circ} \mathrm{C}$ when scaffolds were seeded, served as the control. Samples ( $n=4$ scaffolds) were mixed thoroughly before assay. A Quant-IT ${ }^{\mathrm{TM}}$ PicoGreen ${ }^{\circledR}$ dsDNA Assay Kit (Life Technologies) was used and performed according to the manufacturer's protocol based on $200 \mu \mathrm{L}$ volume for microplate reader analysis. Samples were analyzed in a Modulus II microplate multimode reader using a filter of $490 \mathrm{~nm} \mathrm{Ex/510-}$ $570 \mathrm{~nm}$ Em.

RNA isolation. Cell-seeded scaffolds after the 24- and 48 -h growth periods were snap-frozen in $350 \mu \mathrm{L}$ TRI$\mathrm{zol}^{\circledR}$ (Sigma) and stored at $-80^{\circ} \mathrm{C}$ until preparation. On thawing, the scaffolds were homogenized using a TissueRuptor $^{\mathrm{TM}}$ device (Qiagen) and centrifuged at
$12,000 \mathrm{rpm}$ to obtain an aqueous layer and this was subjected to a chloroform extraction and 70\% ethanol precipitation. The RNA was then prepared using an RNeasy ${ }^{\circledR}$ kit (Qiagen) according to the manufacturer's protocol. The RNA $(100 \mathrm{ng} / \mu \mathrm{L})$ was used to prepare cDNA using ImProm-II ${ }^{\mathrm{TM}}$ Reverse Transcription System (Promega) according to the manufacturer's instructions.

Quantitative reverse transcription-polymerase chain reaction. The quantitative reverse transcriptionpolymerase chain reaction (qRT-PCR) was performed in triplicate using three independent cDNA samples with additional respective RT- samples to investigate gene expression after seeding on scaffolds. SensiFAST ${ }^{\mathrm{TM}}$ SYBR $^{\circledR}$ Hi-ROX (Bioline) was used in the reaction and the reaction was performed using a LightCycler ${ }^{\circledR} 480$ Instrument II (Roche Life Science) for standard program of 45 cycles. Relative quantification of the RT-PCR results was carried out using the $2^{\wedge^{-\Delta \Delta \text { ct }} \text { method. }}{ }^{44,37}$ Forward and reverse primer sequences (Sigma) were as follows: Glyceraldehyde 3-phosphatedehydrogenase (GAPDH): forward primer '5-GTCTCCTCTGACTTC AACAG-3', reverse primer, '5-GTTGTCATACCAGGA AATGAG-3'; vascular endothelial growth factor A (VEGFA): forward primer '5-AGACCAAAGAAAGAT AGAGCAAGACAAG-3', reverse primer '5-GGCAGC GTGGTTTCTGTATCG-3'; matrix metalloproteinase 1 (MMP1): forward primer '5-AGCTAGCTCAGGAT GACATTGATG-3', reverse primer 5'-GCCGATGGGC TGGACAG-3'; von Willebrand factor $(v W F)$ : forward primer 5'-GCAGTGGAGAACAGTGGTG-3', reverse primer 5'-GTGGCAGCGGGCAAAC-3'; Ang1: forward primer $5^{\prime}$-ATTCTGAATGGTGGGGAGCA- ${ }^{\prime}$, reverse primer $5^{\prime}$ - TGTGCTGGGATGGGAAAGAT-3'; platelet/endothelial cell adhesion molecule (PECAM/ CD31): forward primer $5^{\prime}$ - ATTGCAGTGGTTATCAT CGGAGTG-3', reverse primer 5'-CTCGTTGTTGGAG TTCAGAAGTGG-3'; and tissue inhibitor of matrix metalloproteinase-2 (TIMP2): forward primer $5^{\prime}$-AATG CAGATGTAGTGATCAGG-3', reverse primer $5^{\prime}$-TCT ATATCCTTCTCAGGCCC-3'.

\section{Statistical analysis}

Data are presented as average \pm standard error mean. Statistical significance was determined by performing one-way ANOVA with $n=4$ for protein quantitation assay, CellTiter-blue cell viability assay, and the DNA quantitation assay. For qRT-PCR, $n=3$ and for compression testing, $n=3$. All data presented with significance accepted $p<0.05$. 


\section{Results}

\section{Evaluation of scaffold properties}

Retainment of ECSFs. The level of protein released into or extracted from different conditioning fluids was investigated. The protein concentration in the conditioning fluids was measured after agitation with the scaffolds to show the influence in processing methods. The protein released into the PBS group had an average concentration of $0.32 \mu \mathrm{g} / \mu \mathrm{L}$ (as the collagen scaffold itself is a source of protein), while in the BM group this was higher at $0.35 \mu \mathrm{g} / \mu \mathrm{L}$, due to the additional components present within the media. In addition, the $\mathrm{ABM}$ group had the largest concentration at $0.4 \mu \mathrm{g} / \mu \mathrm{L}$, with the presence of ECSFs in the media. In the functionalized groups, which showed significant difference between PBS E/N $(0.3 \mu \mathrm{g} / \mu \mathrm{L})$ and BM E/N $(0.31 \mu \mathrm{g} / \mu \mathrm{L})$, these displayed $25 \%$ and $22.5 \%$ less protein compared to the $\mathrm{ABM}$ group, respectively. The surface functionalization step demonstrated that the ECSFs were retained in the scaffolds, as shown by the reduction of free protein constituents found in the media (conditioning fluid) observed for these groups, with the ABM E/N group $(0.35 \mu \mathrm{g} / \mu \mathrm{L})$ having $12.5 \%$ less in the conditioning fluid compared to the (nonfunctionalized) ABM scaffolds, with a similar trend being shown in the other respective groups (Fig. 2).

Scaffold integrity. In these experiments, we assessed the effect of postmodification of the scaffolds, due to soaking and/or $\mathrm{E} / \mathrm{N}$ surface functionalization within agitation conditions and to determine if the mechanical

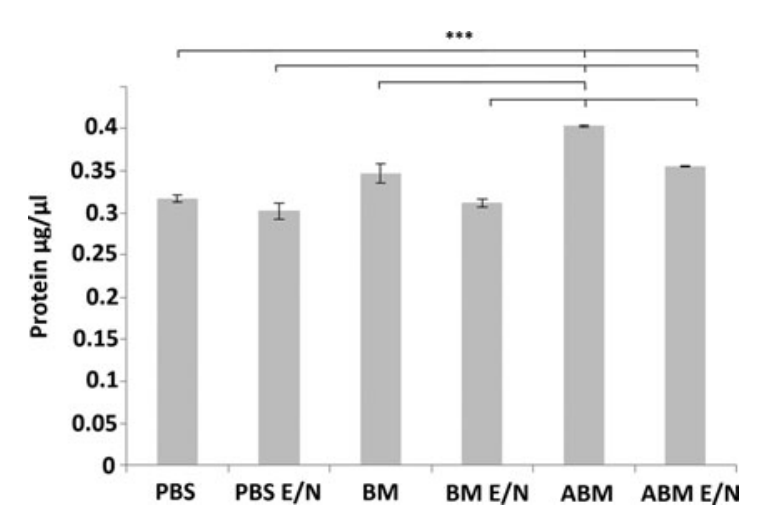

FIG. 2. Protein quantitation of media samples $24 \mathrm{~h}$ postscaffold incubation and before cell seeding. Statistical significance between groups denoted by ${ }^{* *} p<0.01$. integrity was modified. The compression properties of the collagen scaffolds were tested, as was the corresponding surface topography analyzed by SEM. Large differences in Young's modulus were seen at low strain intervals (10-20\%) with a maximum of $50 \%$ difference observed between PBS shaken $(0.4 \mathrm{kPa})$ and unshaken $(0.20 \mathrm{kPa})$. At a high strain interval of $50-60 \%$, the compression difference between PBS shaken $(3.08 \mathrm{kPa})$ and PBS unshaken $(2.78 \mathrm{kPa})$ was reduced to $9.7 \%$ difference. No statistical significant differences were shown between the groups throughout the intervals of the Young's modulus (Table 1.). The surface topography between the scaffold groups showed no vast difference in the macroporous or microporous structure of the collagen (Fig. 3.) with pore sizes varying between $50-200 \mu \mathrm{m}$ approximately across the surface.

\section{Assessment of scaffold functionality}

EC attachment and viability. The ability of cells to attach to the scaffolds was assessed and also their viability once attached to the scaffolds (Fig. 4A). The number of attached viable cells (NAVC) after $24 \mathrm{~h}$ displayed a significant progressive increase across the six scaffold conditions with $\mathrm{ABM}$ scaffolds $\left(30 \times 10^{3}\right.$ cells attached) compared to $33 \%$ and $10 \%$ less attached cells in $\mathrm{BM}$ and PBS scaffolds, respectively. The E/N treated scaffolds showed a greater NAVC than untreated scaffolds across all groups. The NAVC were most profound with ABM E/N scaffolds $\left(35 \times 10^{3}\right.$ cells attached) compared to $71 \%$ less attached cells in PBS scaffolds $\left(10 \times 10^{3}\right.$ cells attached). However, at $48 \mathrm{~h}$ there was an increase in the NAVC, which was significantly greater in all these scaffold groups, with the $\mathrm{ABM} \mathrm{E} / \mathrm{N}$ scaffolds $\left(110 \times 10^{3}\right.$ cells attached) compared to $45 \%$ less cells attached in PBS E/N scaffolds. Comparing the difference between the 24- and 48-h values of NAVC within the six conditions, the level increased exponentially. The amount of DNA retained on the scaffolds from cell attachment showed the same trend across the scaffold groups at $24 \mathrm{~h}$. This was then further increased within these scaffold groups at $48 \mathrm{~h}$, with $\mathrm{ABM} \mathrm{E} / \mathrm{N}$ showing the greatest concentration of DNA retained on the scaffold at $1500 \mathrm{ng} / \mathrm{mL}$ (Fig. 4B). However, the difference in DNA concentration between the groups at 24 and $48 \mathrm{~h}$ is not exponential unlike the NAVC (described above). Visual microscopy using Live/Dead Viability/ Cytotoxicity assay showed NAVC on the scaffolds, with the greatest amount on the ABM E/N scaffolds (Fig. 5). 
Table 1. Scaffold Compression Displaying Young's Modulus (kPa) Among Four Scaffold Conditions

\begin{tabular}{|c|c|c|c|c|c|c|c|c|c|c|c|c|}
\hline \multirow[b]{3}{*}{ Young's modulus (kPa) } & \multicolumn{12}{|c|}{$\%$ Compression } \\
\hline & \multicolumn{2}{|c|}{$0-10$} & \multicolumn{2}{|c|}{$10-20$} & \multicolumn{2}{|c|}{$20-30$} & \multicolumn{2}{|c|}{$30-40$} & \multicolumn{2}{|c|}{$40-50$} & \multicolumn{2}{|c|}{$50-60$} \\
\hline & Mean & SD & Mean & SD & Mean & SD & Mean & SD & Mean & SD & Mean & SD \\
\hline PBS unshaken & 0.20 & 0.20 & 0.62 & 0.07 & 1.01 & 0.04 & 1.13 & 0.12 & 1.62 & 0.27 & 2.78 & 0.60 \\
\hline PBS shaken & 0.40 & 0.18 & 0.71 & 0.09 & 1.05 & 0.11 & 1.29 & 0.16 & 1.79 & 0.32 & 3.08 & 0.79 \\
\hline PBS E/N unshaken & 0.32 & 0.10 & 0.81 & 0.30 & 1.18 & 0.01 & 1.26 & 0.19 & 1.58 & 0.23 & 2.28 & 0.58 \\
\hline PBS E/N shaken & 0.22 & 0.22 & 0.57 & 0.36 & 1.02 & 0.12 & 1.20 & 0.14 & 1.59 & 0.32 & 2.29 & 0.72 \\
\hline
\end{tabular}

E/N, (1-(3-Dimethylaminopropyl)-3-ethylcarbodiimide and NHS-hydroxysulfosuccinimide); PBS, phosphate-buffered saline; SD, standard deviation.

Gene expression of ECs on scaffolds. The analysis of gene expression accessed the functionality of the recipient ECs (seeded) and determined if the scaffold preparation method effected the EC response in terms of expression of key angiogenic and regulatory genes (Figs. 6 and 7). The results indicate a progressive increase in notably VEGFA and Ang1, across all scaffold groups, with ABM scaffolds showing the greatest increase of gene expression, further enhanced by $\mathrm{E} / \mathrm{N}$ surface functionalization. This $\mathrm{ABM} \mathrm{E} / \mathrm{N}$ group showed the greatest level of expression compared to the lowest level with PBS scaffolds and this was significantly sixfold and threefold higher in VEGFA and
Ang1, respectively, at $24 \mathrm{~h}$. These levels increased 6.5fold higher and 3.5-fold higher at $48 \mathrm{~h}$. The key functional gene CD31 was also increased in all groups, with the greatest level in the ABM E/N scaffolds. For the same comparison with PBS scaffolds, the levels were threefold higher at $24 \mathrm{~h}$ and significantly 2.5 fold higher at $48 \mathrm{~h}$. The $v W F$ expression showed marginal differences when compared across groups, with the largest increase (twofold higher) in PBS scaffolds between the 24 - and 48 -h time point. MMP1 was significantly twofold lower in the E/N functionalized scaffolds at 24 and $48 \mathrm{~h}$ when compared to untreated scaffolds. Conversely, the expression of TIMP2, showed
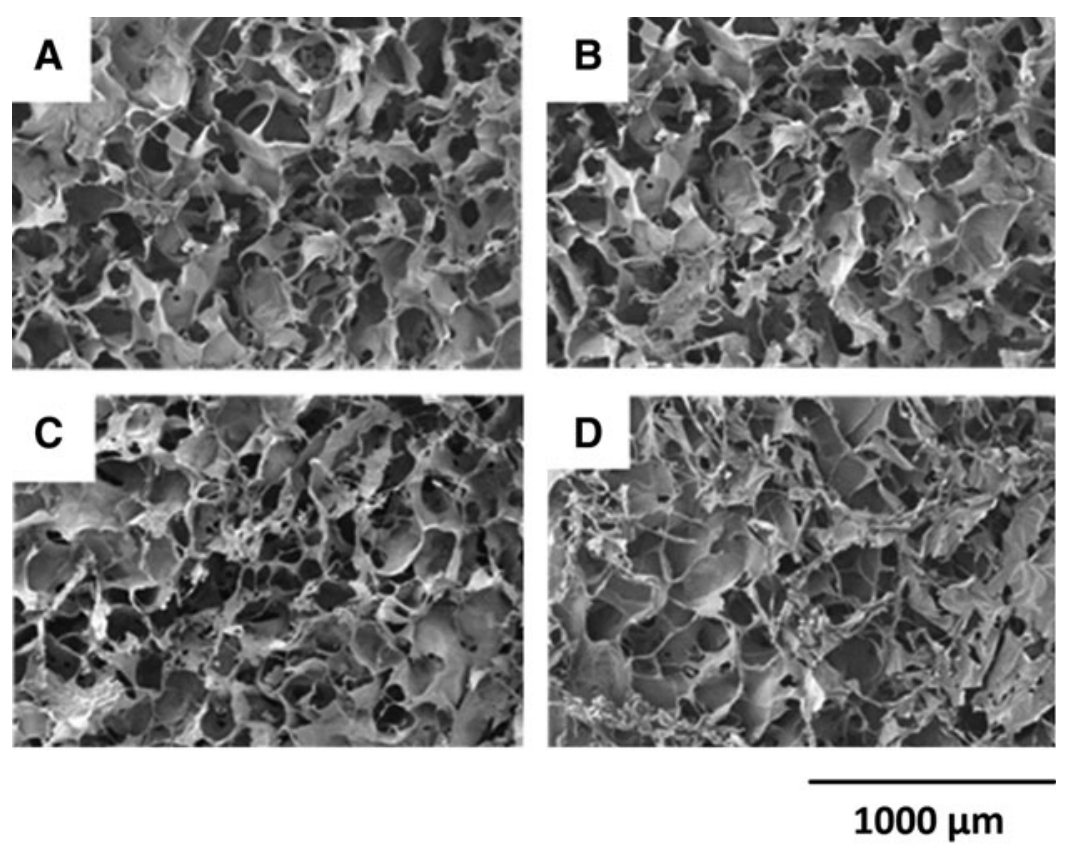

FIG. 3. Scanning electron microscopy images of collagen scaffolds postmodification. (A) PBS unshaken; (B) PBS shaken; (C) PBS E/N unshaken; (D) PBS E/N shaken. E/N, (1-(3-Dimethylaminopropyl)-3-ethylcarbodiimide and NHS-hydroxysulfosuccinimide); PBS, phosphate-buffered saline. 

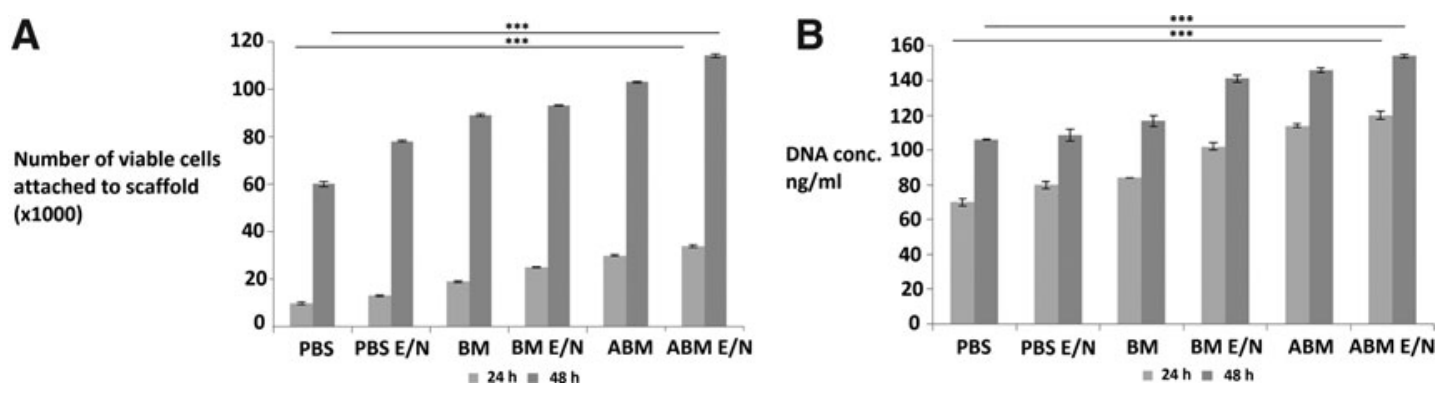

FIG. 4. The number of viable cells attached to scaffolds (A); DNA quantification of scaffolds (B) at 24 and $48 \mathrm{~h}$ postcell seeding. Statistical significance between groups denoted by ${ }^{* *} p<0.01$.
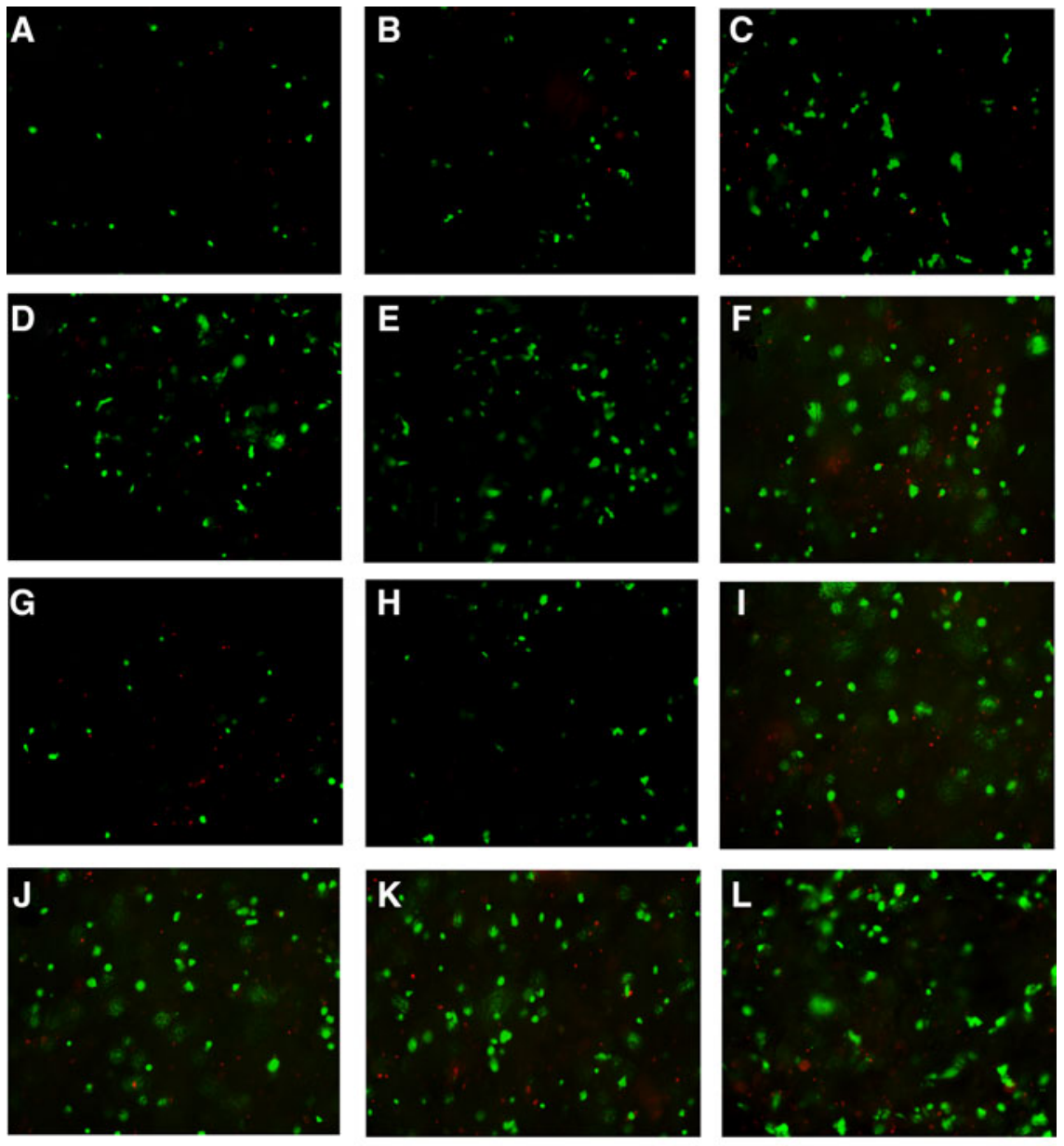

\section{$100 \mu \mathrm{m}$}

FIG. 5. Live/Dead ${ }^{\circledR}$ Viability/Cytotoxicity assay of ECs bound to collagen scaffolds at $24 \mathrm{~h}$ postcell seeding: (A) PBS; (B) PBS E/N; (C) BM; (D) BM E/N; (E) ABM; (F) ABM E/N. Then, at $48 \mathrm{~h}$ postcell seeding: (G) PBS; (H) PBS E/N; (I) $B M$; (J) BM E/N; (K) ABM; (L) ABM E/N. Green cell staining represents calcein AM dye corresponding to viable cells, red cell staining represents Ethd-1 dye and corresponds to apoptotic or dead cells. Magnification used $\times 40$ objective lens and scale bar represents $100 \mu \mathrm{m}$. 

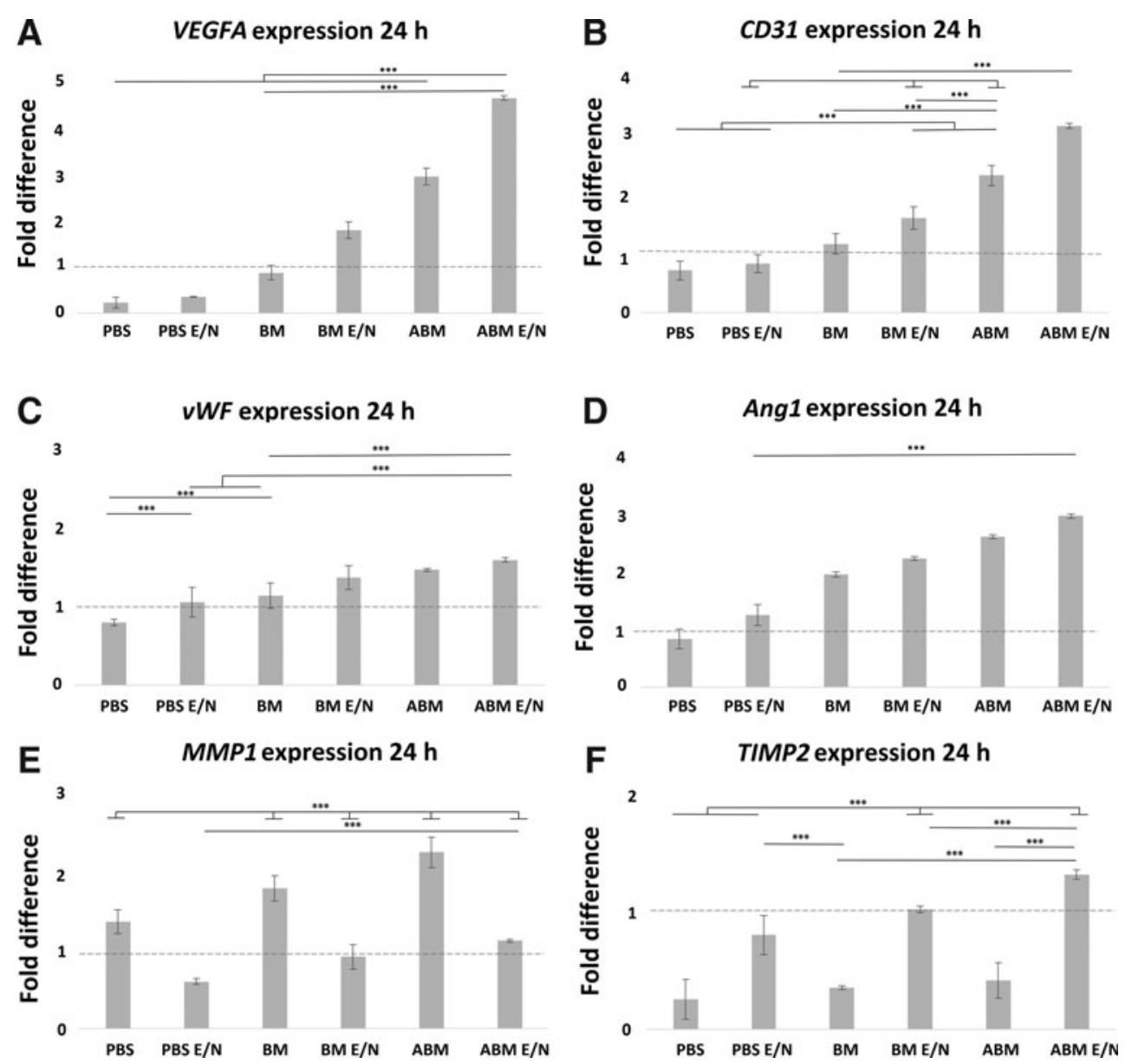

FIG. 6. The qRT-PCR of mRNA expression of genes: (A) VEGFA; (B) CD31; (C) vWF; (D) Ang1; (E) MMP1; (F) TIMP2 at $24 \mathrm{~h}$ postcell seeding on collagen scaffolds. The mRNA expression of these genes ( $y$-axis) was normalized to GAPDH and relative to an EC CDNA-positive control expression (dotted line). Error bars represent $\pm 1 \mathrm{SD}, n=3$ of delta CT value. Ang1, angiopoietin-1; MMP1, matrix metalloproteinase 1; qRT-PCR, quantitative reverse transcription-polymerase chain reaction; SD, standard deviation; TIMP2, tissue inhibitor of matrix metalloproteinase-2; VEGFA, vascular endothelial growth factor $A$; $v W F$, von Willebrand factor.

a significant increase (twofold) in the $\mathrm{E} / \mathrm{N}$ scaffolds at 24-48 h.

\section{Discussion}

The majority of recent studies have used the incorporation of recombinant factors to enhance the performance of TE scaffolds for specific treatments. This can often be complex with varying success, especially when multifactors are used. ${ }^{45}$ An alternative approach to produce the growth factors or proteins is by the use of cell secreted factors. This has been previously achieved by one of the two methods: by the use of cell feeder layers or by obtaining conditioned media. One successful strategy used the MSC-derived conditioned medium that promoted proliferation of cardiac progenitor cells, inhibited apoptosis induced by hypoxia and serum starvation, and, furthermore, upregulated expression of a cardiomyocyterelated gene. ${ }^{46}$ This strategy of paracrine cell secretion has been utilized in many regenerative medical applications, namely with the use of stem cells, through which the paracrine secretion from these cells elicits a response in recruitment of host cells to the tissue environment. ${ }^{47,48}$

In this study, we generated a conditioned media in a bovine-free serum containing the endogenous ECSFs and attached this to the scaffold using a number of techniques. This process demonstrated an increase in 

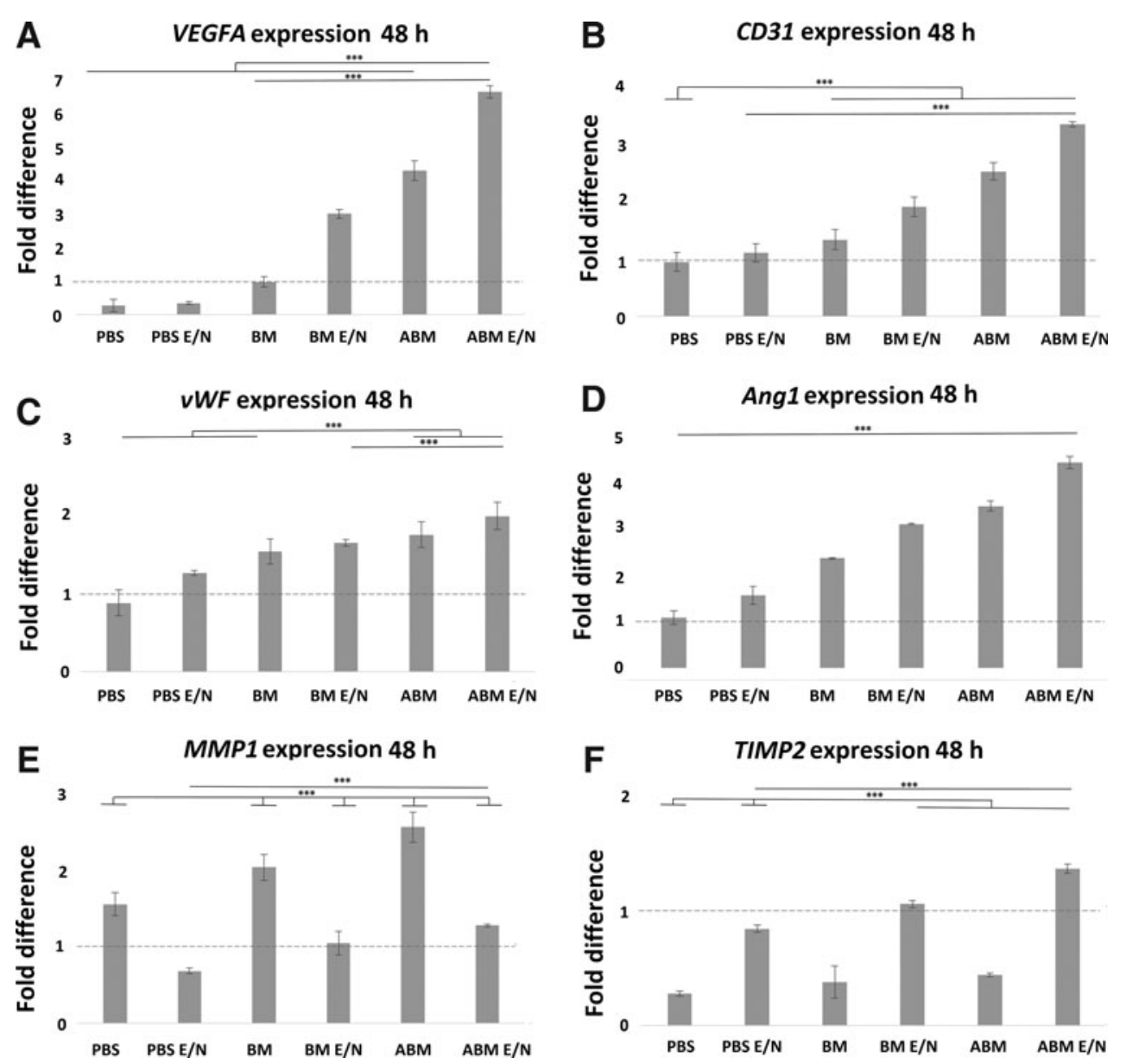

FIG. 7. The qRT-PCR of mRNA expression of genes: (A) VEGFA; (B) CD31; (C) vWF; (D) Ang1; (E) MMP1; (F) TIMP2 at $48 \mathrm{~h}$ postcell seeding on collagen scaffolds. The mRNA expression of these genes ( $y$-axis) was normalized to GAPDH and relative to an EC CDNA-positive control expression (dotted line). Error bars represent $\pm 1 S D, n=3$ of delta $C T$ value.

the level of protein present initially by conditioning scaffolds using BM but more so by using a cell conditioned media (ABM) scaffold. By using a surface crosslinking reaction, we were able to retain and further enhance the conditioned scaffolds and show a greater significant effect in viable cell attachment when these scaffolds have the presence of ECSFs. Nevertheless, the crosslinking reaction served to increase the retention of bound factors upon agitation of BM and ABM scaffold conditions and even enhanced the performance of PBS scaffolds. The further benefits of also using a crosslinking approach such as $\mathrm{E} / \mathrm{N}$, proved not only to unaffect the collagen structural and mechanical integrity but to also slightly enhance the stability of any collagen degradation at $48 \mathrm{~h} .{ }^{49} \mathrm{E} / \mathrm{N}$ crosslinking has been widely used in the immobilization of recombinant growth factors to collagen scaffolds, ${ }^{15-17}$ but here we were also able to demonstrate a stable sustained effect when immobilizing media.

The key finding was that we determined an enhancement effect from this scaffold modification method. This was initially observed using BM and became more profound when $A B M$ scaffolds were used and then further increased by functionalizing with $\mathrm{E} / \mathrm{N}$, displaying significant differences between the groups tested. To represent the phenotype from the attached recipient cells, key gene expression was evaluated. There was also an unaltered endothelial phenotypic response from the attached autologous cells in serumfree conditions; however, there was an enhanced effect 
in angiogenic genes. In addition, we were able to show that the collagen integrity was stable between 24 and $48 \mathrm{~h}$, as $M M P 1$ representing collagen degradation was reduced when scaffolds were $\mathrm{E} / \mathrm{N}$ treated. Likewise, the inverse expression of TIMP 2 representing collagen integrity was increased when scaffolds were $\mathrm{E} / \mathrm{N}$ treated.

While the preliminary findings of this study are promising, there are important limitations and other parameters that exist should be considered. An important limitation is in the scaffold type used, which does not have potential as a vascular substitute, however, there is potential to use this novel conditioning process on other scaffolds types. In addition, there are limitations in the process used to produce the conditioned media, which could be modified to adjust the secreted factors produced. A number of mechanisms could be used to achieve this, such as modification to the serum-free culture ${ }^{50}$ or by exploiting hypoxic conditions to over produce secreted factors. ${ }^{51}$ Furthermore, the long-term activity could be investigated to access the potential for an off-the-shelf scaffold approach using this processing technique. Nevertheless, these studies have shown the potential of a cell secretion method for scaffold applications and also provide this method within a serum-free environment.

\section{Conclusions}

In this study, we have demonstrated a scaffold model utilizing a novel cell secreted method for specifically ECs. Taken together, our results and the core principle of this method highlight the potential that could be extended to other cell types, tissue environments, and suitable scaffold materials in tissue engineering and regenerative medicine applications. This strengthens the case for its potential as a translatable clinical process for improvement in scaffold performance.

\section{Acknowledgments}

The authors thank Stephen Mitchell at the Institute of Molecular Plant Sciences at the University of Edinburgh for assistance with sample preparation and SEM, Dr Siobhan Dunphy for assistance with cell imaging, and Professor Alistair Elfick for the use of his laboratory equipment. This research work is funded by an Engineering and Physical Sciences Research Council (EPSRC) Doctoral Training Partnership (DTP) Studentship.

\section{Author Disclosure Statement}

No competing financial interests exist.

\section{References}

1. Ravi S, Chaikof EL, et al. Biomaterials for vascular tissue engineering. Regen Med. 2010;5:107-120.

2. Khan OF, Sefton MV, et al. Endothelialized biomaterials for tissue engineering applications in vivo. Trends Biotechnol. 2011;29:379-387.

3. Stegemann JP, Kaszuba SN, Rowe SL, et al. Review: advances in vascular tissue engineering using protein-based biomaterials. Tissue Eng. 2007;13:2601-2613.

4. Piterina AV, Callanan A, Davis $L$, et al. Extracellular matrices as advanced scaffolds for vascular tissue engineering. Biomed Mater Eng. 2009;19:333-348.

5. Goonoo N, Bhaw-Luximon A, Bowlin GL, et al. An assessment of biopolymer- and synthetic polymer-based scaffolds for bone and vascular tissue engineering. Polym Int. 2013;62:523-533.

6. Gu L, Zhao R, Spencer R, et al. Development of novel biodegradable polymer scaffolds for vascular tissue engineering. Tissue Eng Part A. 2011;17:1191-1200.

7. Cleary MA, Geiger E, Grady C, et al. Vascular tissue engineering: the next generation. Trends Mol Med. 2012;18:394-404.

8. Naito Y, Shinoka T, Duncan D, et al. Vascular tissue engineering: towards the next generation vascular grafts. Adv Drug Deliv Rev. 2011;63:312-323.

9. Song Y, Feijen J, Grijpma DW, et al. Tissue engineering of small-diameter vascular grafts: a literature review. Clin Hemorheol Microcirc. 2011;49:357-374.

10. Seifu DG, Purnama A, Mequanint K, et al. Small-diameter vascular tissue engineering. Nat Rev Cardiol. 2013;10:410-421.

11. Boccafoschi F, Habermehl J, Vesentini S, et al. Biological performances of collagen-based scaffolds for vascular tissue engineering. Biomaterials. 2005;26:7410-7417.

12. Lu Q, Ganesan K, Simionescu DT, et al. Novel porous aortic elastin and collagen scaffolds for tissue engineering. Biomaterials. 2004;25:5227-5237.

13. Achilli $M$, Mantovani $D$, et al. Tailoring mechanical properties of collagenbased scaffolds for vascular tissue engineering: the effects of $\mathrm{pH}$, temperature and ionic strength on gelation. Polymers. 2010;2:664-680.

14. Glowacki J, Mizuno S, et al. Collagen scaffolds for tissue engineering. Biopolymers. 2008;89:338-344.

15. Shen $\mathrm{YH}$, Shoichet MS, Radisic M, et al. Vascular endothelial growth factor immobilized in collagen scaffold promotes penetration and proliferation of endothelial cells. Acta Biomater. 2008;4:477-489.

16. Odedra D, Chiu LLY, Shoichet M, et al. Endothelial cells guided by immobilized gradients of vascular endothelial growth factor on porous collagen scaffolds. Acta Biomater. 2011;7: 3027-3035.

17. Chiu LLY, Radisic M, et al. Scaffolds with covalently immobilized VEGF and Angiopoietin-1 for vascularization of engineered tissues. Biomaterials. 2010;31:226-241.

18. Chiu LLY, Weisel RD, Li R, et al. Defining conditions for covalent immobilization of angiogenic growth factors onto scaffolds for tissue engineering. J Tissue Eng Regen Med. 2011;5:69-84.

19. Chan TR, Stahl PJ, Yu SM, et al. Matrix-bound VEGF mimetic peptides: design and endothelial-cell activation in collagen scaffolds. Adv Funct Mater. 2011;21:4252-4262.

20. He Q, Zhao Y, Chen B, et al. Improved cellularization and angiogenesis using collagen scaffolds chemically conjugated with vascular endothelial growth factor. Acta Biomater. 2011;7:1084-1093.

21. Des Rieux A, Ucakar B, Mundpenwa BPK, et al. 3D systems delivering VEGF to promote angiogenesis for tissue engineering. J Control Release. 2011;150:272-278.

22. Pang $Y$, Wang $X$, Ucuzian AA, et al. Local delivery of a collagen-binding FGF-1 chimera to smooth muscle cells in collagen scaffolds for vascular tissue engineering. Biomaterials. 2010;31:878-885.

23. Singh S, Wu BM, Dunn JCY, et al. Delivery of VEGF using collagen-coated polycaprolactone scaffolds stimulates angiogenesis. J Biomed Mater Res A. 2012;100:720-727.

24. Kim TG, Shin H, Lim DW, et al. Biomimetic scaffolds for tissue engineering. Adv Funct Mater. 2012;22:2446-2468.

25. Llames S, García-Pérez E, Meana Á, et al. Feeder layer cell actions and applications. Tissue Eng Part B Rev. 2015;21:4:345-353.

26. Havasi $P$, Nabioni $M$, Soleimani $M$, et al. Mesenchymal stem cells as an appropriate feeder layer for prolonged in vitro culture of human induced pluripotent stem cells. Mol Biol Rep. 2013;40:3023-3031.

27. Sugii S, Kida Y, Berggren WT, et al. Feeder-dependent and feederindependent iPS cell derivation from human and mouse adipose stem cells. Nat Protoc. 2011;6:346-358. 
28. Stojkovic $P$, Lako M, Stewart $R$, et al. An autogeneic feeder cell system that efficiently supports growth of undifferentiated human embryonic stem cells. Stem Cells. 2005;23:306-314.

29. Amit $M$, Margulets $V$, Segev $H$, et al. Human feeder layers for human embryonic stem cells. Biol Reprod. 2003;68:2150-2156.

30. Baraniak PR, McDevitt TC, et al. Stem cell paracrine actions and tissue regeneration. Regen Med. 2010;5:121-143.

31. Gnecchi $M$, Zhang $Z, N i$, et al. Paracrine mechanisms in adult stem cell signaling and therapy. Circ Res. 2008;103:1204-1219.

32. Walter MNM, Wright KT, Fuller HR, et al. Mesenchymal stem cell-conditioned medium accelerates skin wound healing: an in vitro study of fibroblast and keratinocyte scratch assays. Exp Cell Res. 2010;316:1271-1281.

33. Angoulvant $D$, Ivanes $F$, Ferrera $R$, et al. Mesenchymal stem cell conditioned media attenuates in vitro and ex vivo myocardial reperfusion injury. J Heart Lung Transplant. 2011:30:95-102.

34. Chen L, Tredget EE, Wu PYG, et al. Paracrine factors of mesenchymal stem cells recruit macrophages and endothelial lineage cells and enhance wound healing. PLoS One. 2008;3:4:e1186.

35. Burlacu A, Grigorescu G, Rosca AM, et al. Factors secreted by mesenchymal stem cells and endothelial progenitor cells have complementary effects on angiogenesis in vitro. Stem Cells Dev. 2013;22:643-653.

36. di Santo S, Yang Z, von Ballmoos M, et al. Novel cell-free strategy for therapeutic angiogenesis: in vitro generated conditioned medium can replace progenitor cell transplantation. PLoS One. 2009;4:5:e5643.

37. Callanan A, Davis NF, McGloughlin TM, et al. Development of a rotational cell-seeding system for tubularized extracellular matrix (ECM) scaffolds in vascular surgery. J Biomed Mater Res B Appl Biomater. 2014;102:781-788.

38. Carroll GT, McGloughlin TM, O'Keeffe LM, at al. Realistic temporal variations of shear stress modulate MMP-2 and MCP-1 expression in arteriovenous vascular access. Cell Mol Bioeng. 2009;2:591-605.

39. Davis, LM, Callanan A, Carroll GT, et al. On the potential of hydrated storage for naturally derived ECMs and associated effects on mechanical and cellular performance. J Biomed Mater Res B Appl Biomater. 2014;102:89-97.

40. Osathanon T, Giachelli CM, Somerman MJ, et al. Immobilization of alkaline phosphatase on microporous nanofibrous fibrin scaffolds for bone tissue engineering. Biomaterials. 2009;30:4513-4521.

41. McCullen SD, Autefage $\mathrm{H}$, Callanan $\mathrm{A}$, et al. Anisotropic fibrous scaffolds for articular cartilage regeneration. Tissue Eng Part A. 2012;18:2073-2083.

42. Oliveira SM, Ringshia R, Legeros RZ, et al. An improved collagen scaffold for skeletal regeneration. J Biomed Mater Res A. 2010;94:371-379.

43. Callanan A, Davis NF, McGloughlin TM, et al. The effects of stent interaction on porcine urinary bladder matrix employed as stent-graft materials. J Biomech. 2014;47:1885-1893.

44. Livak KJ, Schmittgen TD, et al. Analysis of relative gene expression data using real-time quantitative PCR and the 2(-Delta Delta C(T)) method. Methods. 2001;25:402-408.

45. Willerth SM, Rader A, Sakiyama-Elbert SE, et al. The effect of controlled growth factor delivery on embryonic stem cell differentiation inside fibrin scaffolds. Stem Cell Res. 2008;1:205-218.
46. Nakanishi C, Yamagishi M, Yamahara K, et al. Activation of cardiac progenitor cells through paracrine effects of mesenchymal stem cells. Biochem Biophys Res Commun. 2008;374:11-16.

47. Anthony DF, Shiels PG, et al. Exploiting paracrine mechanisms of tissue regeneration to repair damaged organs. Transplant Res. 2013;2:10.

48. Mirotsou M, Jayawardena TM, Schmeckpeper J, et al. Paracrine mechanisms of stem cell reparative and regenerative actions in the heart. J Mol Cell Cardiol. 2011;50:280-289.

49. Vrana NE, Builles $\mathrm{N}$, Kocak $\mathrm{H}$, et al. EDC/NHS cross-linked collagen foams as scaffolds for artificial corneal stroma. J Biomater Sci Polym Ed. 2007:18:1527-1545.

50. Labitzke $R$, Friedl $P$, et al. A serum-free medium formulation supporting growth of human umbilical cord vein endothelial cells in long-term cultivation. Cytotechnology. 2001;35:87-92.

51. Hummitzsch L, Zitta K, Bein B, et al. Culture media from hypoxia conditioned endothelial cells protect human intestinal cells from hypoxia/ reoxygenation injury. Exp Cell Res. 2014;322:62-70.

Cite this article as: Hamilton C, Callanan A (2016) Secreted endothelial cell factors immobilized on collagen scaffolds enhance the recipient endothelial cell environment, BioResearch Open Access 5:1, 61-71, DOI: 10.1089/biores.2016.0003.

\begin{tabular}{|c|}
\hline 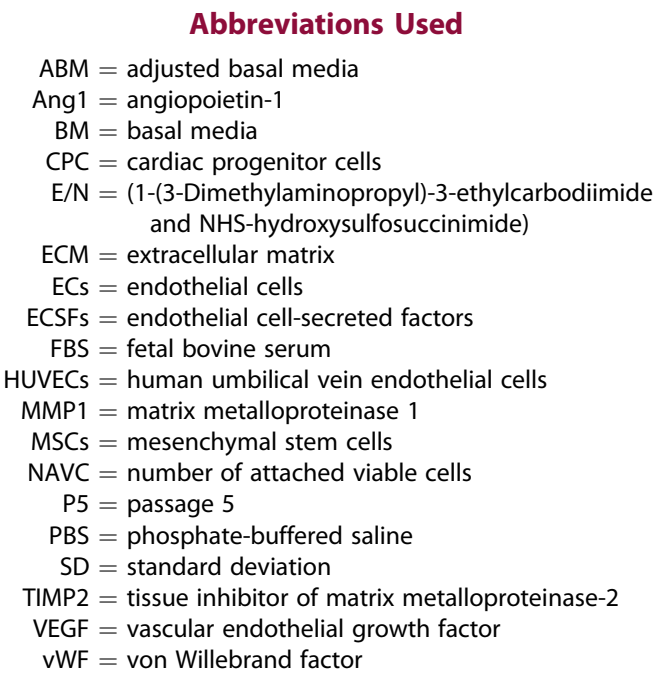 \\
\hline
\end{tabular}

